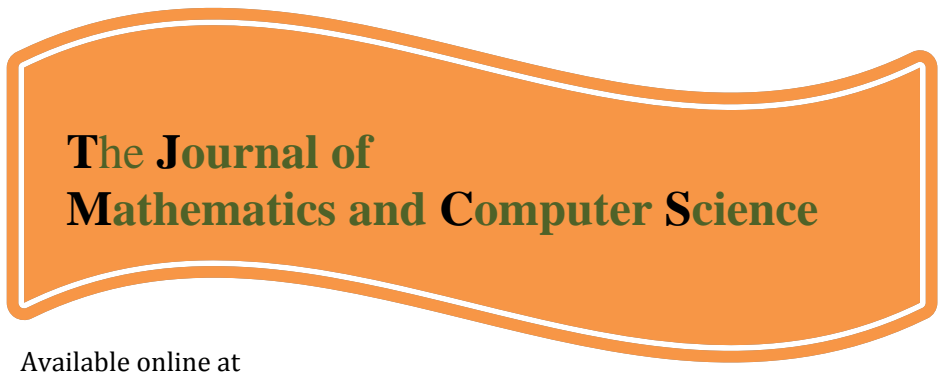

http://www.TJMCS.com

The Journal of Mathematics and Computer Science Vol .2 No.1 (2011) 65-80

\title{
A Fuzzy Optimization Model for Supply Chain Production Planning with Total Aspect of Decision Making
}

\author{
Hamid Reza Feili1 ${ }^{*}$, Mojdeh Hassanzadeh Khoshdooni² \\ Hrfeili@gmail.com \\ Mojdehhassanzadeh@yahoo.com
}

Received: September 2010, Revised: December 2010

Online Publication: January 2011

\begin{abstract}
This paper models supply chain uncertainties by fuzzy sets and develops a fuzzy linear programming model for tactical supply chain planning in a multi-echelon, multiproduct, multi-stage with different methods of manufacturing in each stage, multidistribution centre and multi-period supply chain network. In this approach, the demand, process and supply uncertainties are jointly considered. The aim is to achieve the best use of the available resources and the best method of manufacturing at each stage for a product along the time horizon so that customer demands are met at a minimum cost. The fuzzy model provides the decision maker with alternative decision plans with different degrees of satisfaction.
\end{abstract}

Keywords: Supply Chain Management, Supply Chain Planning, Fuzzy Sets, Uncertainty Modeling.

\section{Introduction}

The concept of supply chain management (SCM), since their appearance in 1982[1], is associated with a variety of meanings. In the eighties, SCM was originally used in the logistical literature to describe a new integrated approach of logistics management through different business functions [2]. Then, this integrated approach was extended outside of the company limits to suppliers and customers [3]. In accordance with the Global Supply Chain Forum [4], the SCM is the integration of key business processes, from final users to original suppliers providing products, services and information which add value to clients,

\footnotetext{
$1^{*}$. Assistant Professor, Industrial Engineering, Alzahra University

2. B.S, Industrial Engineering, Alzahra University
} 
shareholders, etc. This paper is related to one of these key business processes: the supply chain production planning.

Supply chain production planning consists of the coordination and the integration of key business activities carried out from the procurement of raw materials to the distribution of finished products to the customer [5]. Here, tactical models concerning mainly about inventory management and resource limitations are the focus of our work. In this context, with the objective of obtaining optimal solutions related to the minimization of costs, several authors have studied the modeling of supply chain planning processes through mathematical programming models, for instance. However, the complex nature and dynamics of the relationships among the different actors of supply chains imply an important grade of uncertainty in the planning decisions [6]. Therefore, uncertainty is a main factor that can influence the effectiveness of the configuration and coordination of supply chains .One of the key sources of uncertainty in any production-distribution system is the product demand. Thus, demand uncertainty is propagated up and down along the supply chain affecting sensibly to its performance [7].

Along the years many researches and applications aimed to model the uncertainty in production planning problems [8]. Different stochastic modelling techniques have been successfully applied in supply chain production planning problems with randomness [9]. However, probability distributions derived from evidences recorded in the past are not always available or reliable. In these situations, the fuzzy set theory, represents an attractive tool to support the production planning research when the dynamics of the manufacturing environment limit the specification of the model objectives, constraints and parameters. Uncertainty can be present as randomness, fuzziness and/or lack of knowledge or epistemic uncertainty [10]. Randomness comes from the random nature of events and deals with uncertainty regarding membership or non-membership of an element in a set. Fuzziness is related to flexible or fuzzy constraints modelled by fuzzy sets. Epistemic uncertainty is concerned with ill-known parameters modelled by fuzzy numbers in the setting of possibility theory [11].

Few studies address the SC planning problem on a medium-term basis (tactical level) which integrates procurement, production and distribution planning activities into a fuzzy environment .The aim of this approach is to simultaneously optimize the decision variables of different functions that have been traditionally optimized sequentially [12]. Moreover, there is a lack of models contemplating the different sources of uncertainty in an integrated manner. Hence in this study, we develop a tactical supply chain model in a fuzzy environment in a multi-echelon, multi-product, multi-level, multi-period supply chain network. In this proposed model, the demand, process and supply uncertainties are considered simultaneously.

In the context of fuzzy mathematical programming, two very different issues can be addressed: fuzzy or flexible constraints for fuzziness, and fuzzy coefficients for lack of knowledge or epistemic uncertainty [13]. The aim of this paper is to propose an SC planning model where the data, associated with all the sources of uncertainty in an SC, are illknown and modeled by trapezoidal fuzzy numbers.

The main contributions of this paper can be summarized as follows:

- Introducing a novel tactical SC planning model by integrating procurement, production and distribution planning activities into a multi- echelon, multiproduct, multi-level and multi-period SC network.

- Achieving a model which contemplates the different sources of uncertainty affecting SCs in an integrated fashion by considering the possible lack of knowledge in 
the data.

The rest of this paper is arranged as follows. Section 2 presents a literature review about fuzzy applications in SC planning. Section 3 proposes a new fuzzy mixedinteger linear programming (FMILP) model for the tactical SC planning under uncertainty. Then in Section

4, the fuzzy model is transformed into an equivalent auxiliary crisp mixed-integer linear programming model and a resolution method that permit the interactive participation of the decision maker in all the steps of the decision process, and the expressing of opinions in linguistic terms is introduced. In Section 5, the behavior of the model in a real-world automobile SC has been evaluated and, finally, the conclusions and directions for further research are provided.

\section{Literature Review}

In [14] a literature survey on SC planning under uncertainty conditions by adopting quantitative approaches is presented. Here, we present a summary, extracted from this paper, about the applications of the Fuzzy Set Theory and the Possibility Theory to different problems related to SC planning:

(a) SC inventory management: [15],[16] described the fuzzy modeling and simulation of an SC in an uncertain environment. Their objective was to determine the stock levels and order quantities for each inventory during a finite time horizon to achieve an acceptable delivery performance at a reasonable total cost for the whole SC [17] .developed a simulation tool, SCSIM, for analyzing SC behavior and performance in the presence of uncertainty modeled by fuzzy sets. [18] developed a methodology to define inventory management policies in an SC, which was based on the echelon stock concept [19], and the Fuzzy Set Theory was used to model the uncertainty associated with both demand and inventory costs.[20] proposed a fuzzy logic approach to reduce the bullwhip effect [21] developed a decentralized decision model based on a genetic algorithm which minimizes the inventory costs of an SC subject to the constraint to be met with a specific task involving the delivery of finished goods. The authors used the fuzzy set theory to represent the uncertainty of customer demands, processing times and reliable deliveries [22] presented a new bilevel coordination strategy to control and manage inventories in serial supply chains with demand uncertainty. Firstly, the problem associated with the whole SC was divided into subproblems in accordance with the different parts that the SC was made up of. Secondly, for the purpose of improving the integrated operation of a whole SC, the leader level was defined to be in charge of coordinating inventory control and management by amending the optimization subproblems. This process was to be repeated until the desired level of operation for the whole SC was reached. [23] modeled SC uncertainties with fuzzy sets and developed a possibilistic decision model to determine the SC configuration and inventory policies that minimize the total SC costs subject to also fulfilling the target service time of the end-product. They assumed that sourcing options differed in terms of their direct costs and lead-times. Fuzzy sets were used to represent fluctuating customer demands, uncertain lead-times, and unreliable supply deliveries (in 
terms of delay time). A fuzzy SC model extended from [21] was used to evaluate the performance of the entire SC directly. A genetic algorithm approach integrated with the proposed fuzzy SC model was developed to determine the optimal SC configuration and the order-up-to level for each stage at the same time.

(b) Vendor selection: [24] presented a fuzzy goal programming approach which was applied to the problem of selecting vendors in an SC. This problem was posed as a mixed-integer and fuzzy goal programming problem with three basic objectives to minimize the net cost of the vendors network, rejects within the network, and delays in deliveries. With this approach, the authors used triangular membership functions for each fuzzy objective. The solution method was based on the intersection of membership functions of the fuzzy objectives by applying the min-operator. Then, [25] solved the same problem using the multi- objective fuzzy programming approach proposed by [26], [27] addressed the problem of adequately selecting suppliers within an SC. For this purpose, they devised a fuzzy-based multi-objective mathematical programming model where each objective may be assigned a different weight.The objectives considered were related to cost cuts, increased quality and to an increased service of the suppliers selected. The imprecise elements considered in this work were to meet both objectives and demand. [28] analyzed the uncertainty prevailing in integrated steel manufacturers in relation to the nature of the finished good and significant demand by customers. They proposed a new hybrid evolutionary algorithm named endosymbiot icpsychoclonal (ESPC) to decide what to stock and how much as an intermediate product in inventories. They compared ESPC with genetic algorithms and simulated annealing. They concluded the superiority of the proposed algorithm in terms of both the quality of the solution obtained and the convergence time.

(c) Transport planning: [29] considered several assumptions at the supply and demand levels for a given transportation problem in accordance with the kind of information that the decision maker has: crisp values, interval values or fuzzy numbers. For all three cases, classical, interval and fuzzy models for the transportation problem were proposed, respectively. The links among them were provided by focusing on the case of the fuzzy transportation problem, for which solution methods were proposed and discussed. [30] addressed the problem of transporting cement in Taiwan by using fuzzy linear programming models. The author used three approaches based on the works by [31]. [32] [33], who contemplated: the capacities of ports, the fulfilling demand, the capacities of the loading and unloading operations, and the constraints associated with traffic control. [34] developed a method to obtain the membership function of the total transport cost by con-sidering this as a fuzzy objective value where shipment costs, supply and demand were fuzzy numbers. The method was based on the extension principle defined by [35] to transform the fuzzy transport problem into a pair of mathematical programming models. [36] developed an interactive multiobjective linear programming model for solving fuzzy multi-objective transpor- tation problems with a piecewise linear membership function.

(d) Production-distribution planning: [37] addressed the real problem of production and transport related to a manufacturer through a deterministic mathematical programming model which minimized costs in accordance with capacities and demands. Then, the authors developed a mathematical fuzzy programming model. Finally, they presented an outline of the distribution of profits and costs based on the Game Theory. [38] proposed an interactive fuzzy multi-objective linear program- ming model for solving an integrated production-transportation planning problem in supply chains. [39] proposed fuzzy goal-based programming approaches applied to planning 
problems of a collaborative production-distribution type in centralized and decentralized supply chains. The fuzzy elements that the authors considered corresponded to the fulfilment of different objectives related to maximizing profits for manufacturers and distribution centers, retailer cost cuts and minimizing delays in demand in retailers. [40] developed an integrated multi-period, multi-product fuzzy production and distribution aggregate planning model for supply chains by providing a sound trade-off between the filtrate of the fuzzy market demand and the profit. The model was formulated in terms of fuzzy programming and the solution was provided by genetic optimization.

(e) Procurement-production-distribution planning: [41] developed an approach to derive the membership function of the fuzzy minimum total cost of the multi-product, multiechelon, and multi-period SC model when the unit cost of raw materials supplied by suppliers, the unit transportation cost of products, and the demand quantity of products were fuzzy numbers. Recently, [42] proposed a new multi-objective possibilistic mixed-integer linear programming model for integrating procurement, production and distribution planning by considering various conflicting objectives simultaneously along with the imprecise nature of some critical parameters such as market demands, cost/time coefficients and capacity levels. The proposed model and solution method were validated by numerical tests.

As mentioned previously, there is a lack of models which focus on the different sources of uncertainty in an integrated manner, and few studies address the SC planning problem on a medium-term basis which integrates procurement, production and distribution planning activities in a fuzzy environment. Moreover, the majority of the models studied do not apply to supply chains based on real-world cases.

\section{Problem description}

This section outlines the tactical SC planning problem .The can overall problem be stated as follows: Given:

- An SC topology: the number of nodes and type (suppliers, manufacturing plants, warehouses, distribution centers, retailers, etc.).

- Each cost parameter, such as manufacturing, inventory, transportation, demand backlog, etc.

- Manufacture data, processing times, production capacity, overtime capacity, BOM, minimum and maximum production run, etc.

- Transportation data, such as lead-time, transport capacity, etc.

- Procurement data, procurement capacity, etc.

- Inventory data, such as inventory capacity, etc.

- Forecasted product demands over the entire planning periods.

- Waste percentage of received materials from suppliers at each node.

To determine:

- The production plan of each manufacturing node.

- The production run of each manufacturing node.

- The distribution transportation plan between nodes.

- The procurement plan of each supplier node.

- The inventory level of each node. 
- Sales and demand backlog.

The aim is to centralize the multi-node decisions simultaneously in order to achieve the best use of the available resources in the SC along the time horizon so that customer demands are met at a minimum cost.

\subsection{Fuzzy model formulation}

The fuzzy mixed-integer linear programming (FMILP) model for the tactical SC planning proposed by [43] is adopted as the basis of this work. Sets of indices, parameters and decision variables for the FMILP model are defined in the nomenclature (see Table 1 ). Table 2 shows the uncertain parameters grouped according to the uncertainty sources that may be presented in an SC.

FMILP is formulated as follows:

Table 1 : Nomenclature (fuzzy parameters are shown with a tilde: $\sim$ ).

\begin{tabular}{|c|c|}
\hline \multicolumn{2}{|c|}{ Set of indices } \\
\hline $\mathrm{D}$ & Set of destination nodes for transports $(d=1,2 \ldots, D)$ \\
\hline I & Set of products (raw materials, intermediate products, finished goods) $(i=1,2 .$. \\
\hline $\mathrm{J}$ & Set of production resources $(j=1,2 \ldots)$, \\
\hline $\mathrm{L}$ & Set of transports $(1=1,2 \ldots, \mathrm{L})$ \\
\hline $\mathrm{M}$ & Set of stage of production $(\mathrm{m}=1,2, \ldots, \mathrm{M})$ \\
\hline $\mathrm{N}$ & Set of SC nodes $(n=1,2 \ldots, N)$ \\
\hline 0 & Set of origin nodes for transports $(0=1,2 \ldots, 0)$ \\
\hline $\mathrm{P}$ & Set of parent products in the bill of materials $(\mathrm{p}=1,2 \ldots, \mathrm{P})$ \\
\hline $\mathrm{T}$ & Set of planning periods $(\mathrm{t}=1,2 \ldots, \mathrm{T})$ \\
\hline \multicolumn{2}{|c|}{$\begin{array}{l}\text { Objective function } \\
\text { cost coefficients }\end{array}$} \\
\hline$\tilde{\mathrm{P}} \mathrm{C}_{\mathrm{njt}}$ & Variable production cost per unit of product $i$ on $j$ at $n$ in $t$ \\
\hline Õ $C_{n j t}$ & Overtime cost of resource $\mathrm{j}$ at $\mathrm{n}$ in $\mathrm{t}$ \\
\hline U $C_{n j t}$ & Undertime cost of resource $\mathrm{j}$ at $\mathrm{n}$ in $\mathrm{t}$ \\
\hline RMCint & Price of raw material $i$ at $n$ in $t$ \\
\hline$\tilde{\mathrm{T}} \mathrm{C}_{\text {odlt }}$ & Transport cost per unit from o to $d$ by $\mathrm{l}$ in $t$ \\
\hline$\tilde{\mathrm{H}}$ Cint & Inventory holding cost per unit of product $\mathrm{i}$ at $\mathrm{n}$ in $\mathrm{t}$ \\
\hline$\tilde{B} C_{\text {int }}$ & Demand backlog cost per unit of product i at $n$ in $t$ \\
\hline \multicolumn{2}{|c|}{ General data } \\
\hline$\beta$ & Waste percentage recieved materials from suppliers \\
\hline Qpint & Quantity of i to produce a unit of $\mathrm{p}$ at $\mathrm{n}$ in $\mathrm{t}$ \\
\hline UPि Snt & Maximum procurement capacity from supplier node $\mathrm{n}$ in $\mathrm{t}$ \\
\hline$\widetilde{D}$ int & Demand of product i at $n$ in $t$ \\
\hline$\tilde{O} R_{n j t}$ & Overtime capacity of resource $\mathrm{j}$ at $\mathrm{n}$ in $\mathrm{t}$ \\
\hline $\mathrm{PC} \mathrm{R}_{\mathrm{njt}}$ & Production capacity of resource $\mathrm{j}$ at $\mathrm{n}$ in $\mathrm{t}$ \\
\hline IP0in & Inventory amount of $\mathrm{i}$ at $\mathrm{n}$ in period 0 \\
\hline LPRinjt & Minimum production run of $i$ on $j$ at $n$ in $t$ \\
\hline UPRinjt & Maximum production run of $i$ on $j$ at $n$ in $t$ \\
\hline B0int & Demand backlog of $\mathrm{i}$ at $\mathrm{n}$ in period 0 \\
\hline SR0iodlt & Shipments of i received at d from o by $\mathrm{l}$ at the beginning of period 0 \\
\hline
\end{tabular}


Hamid Reza Feili, Mojdeh Hassanzadeh Khoshdooni/ TJMCS Vol .2 No.1 (2011) 65-80

\begin{tabular}{|c|c|}
\hline SIP0 $0_{\text {iodlt }}$ & Shipments in progress of i from o to $d$ by $l$ at the beginning of period 0 \\
\hline PT̃ $P_{\text {injt }}$ & Processing time to produce a unit of $\mathrm{i}$ on $\mathrm{j}$ at $\mathrm{n}$ in $\mathrm{t}$ \\
\hline TL̃ $\mathrm{T}_{\text {odlt }}$ & Transport lead-time from o to d by lint \\
\hline PV it & Physical volume of product $\mathrm{i}$ in $\mathrm{t}$ \\
\hline UTC̃ nt & Maximum transport capacity of $\mathrm{l}$ in $\mathrm{t}$ \\
\hline UII $\mathrm{nt}$ & Maximum inventory capacity at $\mathrm{n}$ in $\mathrm{t}$ \\
\hline $\mathrm{X}^{1}$ odlt & $0-1$ function. It takes $\mathbb{1}$ if TLT odlt $>0$, and 0 otherwise \\
\hline $\mathrm{X}^{2}$ odlt & $0-1$ function. It takes $\mathbb{1}$ if TLT odlt $1 / 40$, and 0 otherwise \\
\hline \multicolumn{2}{|c|}{ Decision variables } \\
\hline Pinjt & Production amount of $\mathrm{i}$ on $\mathrm{j}$ at $\mathrm{n}$ in $\mathrm{t}=\mathrm{PT}$ injt $>0$ \\
\hline PRinjt & Production run of $\mathrm{i}$ on $\mathrm{j}$ at $\mathrm{n}$ in $\mathrm{t}$ \\
\hline NPRinjt & Number of production runs of $i$ produced on $\mathrm{j}$ at $\mathrm{n}$ in $\mathrm{t}$ \\
\hline SPint & Supply of product i from $n$ in $t$ \\
\hline Bint & Demand backlog of i at $n$ in $\mathrm{t}=\mathrm{DBC}$ int $>0$ \\
\hline TQ iodlt & Transport quantity of i from o to $\mathrm{d}$ by $\mathrm{l}$ in $\mathrm{t}=\mathrm{o}<>\mathrm{d}$; $\mathrm{TC}_{\text {odlt }}>0 ; \mathrm{IC}_{\mathrm{i} ; \mathrm{n} 1 / 4 \mathrm{~d} ; \mathrm{t}}>0$ \\
\hline SRiodlt & $\begin{array}{l}\text { Shipments of } \mathrm{i} \text { received at } \mathrm{d} \text { from o by } \mathrm{l} \text { at the beginning of period } \mathrm{t}=\mathrm{o}<>\mathrm{d} \text {; } \\
\mathrm{TC}_{\text {odlt }}>0 ; \mathrm{IC} \mathrm{i} ; \mathrm{n}^{1 / 4} \mathrm{~d} ; \mathrm{t}>0\end{array}$ \\
\hline SIPiodlt & $\begin{array}{l}\text { Shipments in progress of } \mathrm{i} \text { from o to } \mathrm{d} \text { by } \mathrm{l} \text { at the beginning of period } \mathrm{t}=\mathrm{o}<>\mathrm{d} \text {; } \\
\mathrm{TC}_{\mathrm{odlt}}>0 ; \mathrm{IC}_{\mathrm{i}} ; \mathrm{n}^{1} 1 / 4 \mathrm{~d} ; \mathrm{t}>0 ; \mathrm{TLT}_{\text {odlt }}>0\end{array}$ \\
\hline FTLT iodlt & Transport lead-time for $\mathrm{i}$ from o to $\mathrm{d}$ by $\mathrm{l}$ in $\mathrm{t}$ (onlyused in the fuzzy model) \\
\hline Iint & Inventory amount of $\mathrm{i}$ at $\mathrm{n}$ at the end of period $\mathrm{t}$ \\
\hline PQ int & Purchase quantity of $\mathrm{i}$ at $\mathrm{n}$ in $\mathrm{t}=\mathrm{RMC}$ int $>0$ \\
\hline OT njt & Overtime for resource $\mathrm{j}$ at $\mathrm{n}$ in $\mathrm{t}$ \\
\hline UT njt & Undertime for resource $\mathrm{j}$ at $\mathrm{n}$ in $\mathrm{t}$ \\
\hline YPinjt & Binary variable indicating whether a product $i$ has been produced on $j$ at $n$ in $t$ \\
\hline
\end{tabular}

Table 2 Fuzzy parameters considered in the model.

\begin{tabular}{|c|c|c|}
\hline $\begin{array}{c}\text { Source of uncertainty in supply } \\
\text { chains }\end{array}$ & Fuzzy coefficient & Formulation \\
\hline \multirow[t]{2}{*}{ Demand } & Product demand & int \\
\hline & Demand backlog cost & $\tilde{\mathrm{B}} \mathrm{C}_{\text {int }}$ \\
\hline \multirow[t]{5}{*}{ Process } & Processing time & Pर्T $P_{\text {injt }}$ \\
\hline & Production capacity & PC $R_{n j t}, \tilde{O} R_{n j t}$ \\
\hline & Production costs & $\tilde{P} C_{n j t}, \tilde{O} C_{n j t}, \tilde{U} C_{n j t}$ \\
\hline & Inventory holding cost & $\tilde{\mathrm{H}} \mathrm{C}_{\text {int }}$ \\
\hline & Maximum inventory capacity & UĨ $n t$ \\
\hline \multirow[t]{4}{*}{ Supply } & Transport lead-time & TL̃ $\mathrm{T}_{\text {odlt }}$ \\
\hline & Transport cost & $\tilde{\mathrm{T}} \mathrm{C}_{\text {odlt }}$ \\
\hline & Maximum transport capacity & UTC̃ nt \\
\hline & $\begin{array}{l}\text { Maximum procurement } \\
\text { capacity }\end{array}$ & UP $S_{n t}$ \\
\hline
\end{tabular}

Minimize $Z=\sum_{i=1}^{\mathrm{I}} \sum_{\mathrm{n}=1}^{\mathrm{N}} \sum_{\mathrm{j}=1}^{\mathrm{J}} \sum_{\mathrm{t}=1}^{\mathrm{T}} \sum_{\mathrm{m}=1}^{\mathrm{M}}\left(\mathrm{PC}_{\text {injmt }} \cdot \mathrm{P}_{\mathrm{injm}}\right)+\sum_{n=1}^{N} \sum_{j=1}^{J} \sum_{t=1}^{T}\left(O C_{n j t} \cdot O T_{n j t}+U C_{n j t} \cdot U T_{n j t}\right)+$ $\sum_{i=1}^{I} \sum_{n=1}^{N} \sum_{t=1}^{T}\left(R M C_{i n t} \cdot P Q_{i n t}+H C_{i n t} \cdot I_{i n t}+B C_{i n t} \cdot B_{i n t}\right)+$

$\sum_{i=1}^{I} \sum_{o=1}^{O} \sum_{d=1}^{D} \sum_{l=1}^{L} \sum_{t=1}^{T}\left(T \tilde{C}_{\text {odlt }} \cdot T Q_{\text {iodlt }}\right)$

Subject to

$\sum_{i=1}^{I}\left(P_{\text {injmt }} \cdot P \tilde{T} P_{\text {injmt }}\right) \leq P \tilde{C} R_{\text {njmt }}+\tilde{O} R_{\text {njmt }} \quad \forall n, j, t$

$L P R_{\text {injtm }} \leq P R_{\text {injmt }} \leq U P R_{\text {injmt }}$

$P_{\text {injmt }}=N P R_{\text {injmt }} \cdot P R_{\text {injmt }} \quad \forall i, n, j, t$

$\sum_{m=1}^{M} P_{\text {injmt }} . P T P_{\text {injmt }} \leq P C R_{\text {injt }} . Y P_{\text {injt }}+O R_{\text {injt }} . Y P_{\text {injt }} \quad \forall i, n, j, t$

$P_{\text {injtm }} \geq L P R_{\text {injmt }} . Y P_{\text {injmt }} \quad \forall i, n, j, t$ 


$$
\begin{aligned}
& I_{\text {int }}=I_{\text {in }(t-1)}+\sum_{j=1}^{J} \sum_{m=1}^{M} P_{\text {injmt }}+\sum_{o=1}^{O} \sum_{l=1}^{L} S R_{\text {io.d=nlt }}+P Q_{\text {int }}-\sum_{d=1}^{D} \sum_{l=1}^{L} T Q_{i . o=n . d l t}-S P_{\text {int }}- \\
& p=1 P \text { (Qpint. } j=1 / m=1 M P i=\text { p.njtm }) \quad \forall i, n, t \\
& S R_{\text {iodlt }}=S R O_{\text {iodlt }}+T Q_{\text {iodt } . t-T \tilde{L} T} \quad \forall i, o, d, l, t \\
& S I P_{\text {iodlt }}=S I P 0_{\text {iodlt }}+S I P_{\text {iodlt } .(t-1)}+T Q_{\text {iodlt }}-S R_{\text {iodlt }} \quad \forall i, o, d, l, t \\
& \sum_{\mathrm{i}=1}^{\mathrm{I}} \mathrm{I}_{\text {int }} \cdot \mathrm{PV}_{\mathrm{it}} \leq \tilde{U I} \text { it } \\
& \sum_{\mathrm{i}=1}^{I} \sum_{0=1}^{\mathrm{O}} \sum_{\mathrm{d}=1}^{\mathrm{D}} \mathrm{SIP}_{\text {iodlt }} \cdot \mathrm{PV}_{\mathrm{it}} \cdot X_{\text {odlt }}^{1}+\sum_{\mathrm{i}=1}^{I} \sum_{\mathrm{o}=1}^{\mathrm{O}} \sum_{\mathrm{d}=1}^{\mathrm{D}} \mathrm{TQ}_{\text {iodlt }} \cdot \mathrm{PV}_{\mathrm{it}} \cdot \mathrm{X}_{\text {odlt }}^{2} \leq \tilde{U T C}_{i t} \\
& \sum_{\mathrm{i}=1}^{\mathrm{I}} \mathrm{PQ}_{\text {int }} \leq U \tilde{P}_{\tilde{D}} S_{n t} \\
& \sum_{\mathrm{m}=1}^{M} \mathrm{p}_{\text {injmt }}=\frac{\tilde{D_{\text {int }}}}{1-\beta} \\
& B_{\text {int }}=B_{\text {in }(t-1)}+\tilde{D_{\text {int }}}-S P_{\text {int }} \\
& O T_{n j t}=\sum_{i=1}^{I} \sum_{m=1}^{M}\left(P_{\text {injmt }} \cdot P T \tilde{P}_{\text {injmt }}+P \tilde{C R}_{n j t}\right)+U T_{n j t} \\
& \sum_{n=1}^{N} \sum_{t=1}^{T} S P_{i n t} \leq \sum_{i=1}^{I} \sum_{m=1}^{M}\left(\tilde{D_{i n t}}+B 0_{i n t}\right) \\
& P_{\text {injtm }}, N P R_{\text {injmt }} \geq 0 \quad \forall i, j, n, t, m \\
& S P_{\text {int }}, B_{\text {int }}, I_{\text {int }}, P Q_{\text {int }} \geq 0 \quad \forall i, n, t \\
& S R_{\text {iodlt }}, S I P_{\text {iodlt }}, T Q_{\text {iodlt }} \geq 0 \quad \forall i, o, d, l, t \\
& O T_{n j t}, U T_{n j t} \geq 0 \quad \forall n, j, t
\end{aligned}
$$

Eq. (1) attemps to minimize the total cost. The production costs considering differentiation between regular and overtime production are included in the total cost. It also consider idleness, raw material acquisition, inventory holding, demand backlog and transport. Most of these costs cannot be measured easily since they mainly imply human perception for their estimation. Therefore, these costs are considered uncertain data and are modeled by fuzzy numbers. Only the raw material cost is assumed to be known.

The production time in each stage per period could be lower or equal to the available regular time plus the available overtime for a certain production resource of a node (2). The variable production run of $\mathrm{I}$ in each stage in $\mathrm{j}$ at $\mathrm{n}$ in $\mathrm{t}$ could variate in the defined interval (between minimum and maximum production run). On the other hand, the produced quantity of each product in each planning period must always be a multiple of the selected production lot size (4).

Eqs. (5) and (6) guarantee a minimum production size for the different productive resources of the nodes in the different periods. These equations guarantee that Pinjt will be equal to zero if YPinjt is zero.

Eq. (7) considers to the inventory balance. The inventory of a certain product in a node, at the end of the period, will be equal to the inputs minus the outputs of the product generated in this period. Inputs include the production, transport receptions from other nodes, purchases (if supplying nodes) and the inventory of the previous period. Outputs are related to shipments to other nodes, supplies to customers and the consumption of other products (raw materials and intermediate products) that need to be produced in the node.

Eqs. (8) and (9) control the shipment of products among nodes. The receptions of shipments for a certain product will be equal to the sum of planned deliveries and the shipments carried out in previous periods. In constraint (8), the transport lead-time is considered uncertainty data. On the other hand (9), the shipments in progress will be equal to sum of the initial shipments in progress and shipments from the previous period, and the new shipments initiated in this period minus the new receptions.

Both the transports and inventory levels are limited by the available volume (known approximately). Thus according to Eq. (10), the inventory level for the physical volume of each product must be lower than the available maximum volume for each period (considering uncertainty data). The inventory volume depends on the period to consider the possible increases and decreases of the storage capacity over time. Additionally, the physical volume of the product depends on the time to cope with the possible engineering changes that may occur and affect the dimensions and volume of the 
different products.

On the other hand, the shipment quantities in progress of each shipment in each period multiplied by the volume of the transported products (if the transport time is higher than 0 periods), plus the initiated shipments by each transport in each period multiplied by the volume of the transported products (if the transport time is equal to 0 periods), can never exceed the maximum transport volume for that period (11). The reason for using a different formulation in terms of the transport time among nodes (TLT odlt ) is because the transport in progress will never exist if this value is not higher than zero because all the transport initiated in a period is received in this same period if TLT odlt $=0$. Finally, the transport volume depends on the period to consider the possible increases and decreases of the transport capacity over time.

Eq. (12) limits the purchase quantity of materials for different suppliers at each node and period. Eq. (13) considers the defined amount of waste, so the amount of production of product I should equal to the demand of that product divide by percentage of healthy products. Eq. (14) contemplates the backlog demand management over time. The backlog demand for a product and node in a certain period will be equal (approximately) to the backlog demand of the previous period plus the difference between supply and demand.

Eq. (15) considers that the sum of overtime and undertime production for the different productive resources is equal to the total production time minus the available regular production time plus the idle time. OT njt and UT njt will always be higher or equal to zero if the total production time is higher than the available regular production time, UT njt will be zero as it does not incur in added costs, and OT njt will be positive. Alternatively, if the total production time is lower than the available regular production time, UT njt will be positive and OT njt will be zero.

Conversely, Eq. (16) establishes that the sum of all the supplied products is essentially lower or equal to demand plus the initial backlog demand. At any rate, the problem could easily consider that all the demand is served at the end of last planning period by transforming this inequality equation into

an equality equation. Finally, Eqs. (17)-(20) guarantee the non negativity of the corresponding decision variables.

\section{Solution methodology}

4.1. Transformation of the fuzzy mixed-integer linear programming model into an equivalent crisp model

In this section, we define an approach to transform the fuzzy mixed-integer linear programming model (FMILP) into an equivalent auxiliary crisp mixed-integer linear programming model for tactical SC planning under supply, process and demand uncertainties. According to Table 2, and in order to address the fuzzy coefficients of the FMILP model, it is necessary to consider the fuzzy mathematical programming approaches that integrally consider the fuzzy coefficients of the objective function and the fuzzy constraints: technological and right-hand side coefficients. In this context, several research works exist in the literature, and readers may refer to them ([44] [45]; [46],[478]; [48]; [49]; [50]; [51]). In this paper, we adopt the approach by [49]). The authors proposed a method for solving linear programming problems where all the coefficients were, in general, fuzzy numbers. They introduced a resolution method for this type of problems that permitted the interactive participation of the decision maker (DM) in all the steps of the decision process, and the expressing of opinions in linguistic terms was introduced.

Let us now consider the following linear programming problem with fuzzy parameters: Min $z=\tilde{c} \quad t x$

s.a. $\quad x \in N(\tilde{A} . \tilde{b})=\left\{x \in R^{n} \mid \tilde{a_{i}} x \geq \tilde{b_{i}} \quad i=1 \ldots \ldots m . x \geq 0\right.$ 


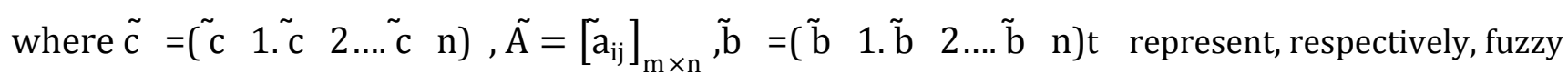
parameters involved in the objective function and constraints. The possibility distribution of fuzzy parameters is assumed to be characterized by fuzzy numbers. $\mathrm{x}=(\mathrm{x} 1, \mathrm{x} 2, \ldots, \mathrm{xn})$ is the crisp decision vector.

The uncertain and/or imprecise nature of the parameters of the problem leads us to compare fuzzy numbers that involve two main problems: feasibility and optimality, therefore it is necessary to answer two questions [49]

(1) How to define the feasibility of a decision vector $x$, when the constraints involve fuzzy numbers.

(2) How to define the optimality for an objective function with fuzzy coefficients.

Several focuses have been developed to solve this problem and to answer these questions (see for example [52]; [53], [54]). A variety of methods for comparing or ranking fuzzy numbers has been reported in the literature ([55]). Different properties have been applied to justify ranking methods, such as: distinguishability, rationality, fuzzy or linguistic representation and robustness. In this paper we use a fuzzy relationship to compare fuzzy numbers [56] that verifies all the suitable properties above and . which, besides, is computationally efficient to solve linear problems because it preserves its linearity.

Thus, by applying the approach described by [56] the problem (21) is transformed into the crisp equivalent parametric linear programming problem defined in (22) where . represents the degree that, at least, all the constraints are fulfilled; that is, . is the feasibility degree of a decision $\mathrm{x}$.

Min EV(c )x (22)

s.a $\left[(1-\alpha) E_{2}^{a_{i}}+\alpha E_{2}^{a_{i}}\right] x \geq \alpha E_{2}^{b_{i}}+(1-\alpha) E_{2}^{b_{i}} \quad i=1 \ldots \ldots m . x \geq 0 \quad \alpha \in[0,1]$

where the expected value of a fuzzy number, noted $\mathrm{EV}(\sim \mathrm{c})$, is the half point of its expected interval [57]: $\operatorname{EV} \tilde{(c)}=\frac{E_{1}^{c}+E_{2}^{c}}{2}$

and if the fuzzy number $\sim \mathrm{c}$ is trapezoidal, its expected interval is easily calculated as follows:

$\mathrm{EI}(\mathrm{c})=\left[\mathrm{E}_{1}^{\mathrm{c}} \cdot \mathrm{E}_{2}^{\mathrm{c}}\right]=\left[\frac{1}{2}\left(\mathrm{c}_{1}+\mathrm{c}_{2}\right) \cdot \frac{1}{2}\left(\mathrm{c}_{3}+\mathrm{c}_{4}\right)\right]$

If (21) was a less than or equal type constraint, 6 , this could be transformed into the following equivalent crisp constraint:

$\left[(1-\alpha) \mathrm{E}_{1}^{\mathrm{a}_{\mathrm{i}}}+\alpha \mathrm{E}_{2}^{\mathrm{a}_{\mathrm{i}}}\right] \mathrm{x} \leq \alpha \mathrm{E}_{1}^{\mathrm{b}_{\mathrm{i}}}+(1-\alpha) \mathrm{E}_{2}^{\mathrm{b}_{\mathrm{i}}} \quad \mathrm{i}=1 \ldots \ldots \mathrm{m} . \mathrm{x} \geq 0 \quad \alpha \in[0,1]$

Otherwise, if (21) was a equality type constraint, this could be transformed into two equivalent crisp constraints:

$$
\begin{aligned}
& {\left[\left(1-\frac{\alpha}{2}\right) \mathrm{E}_{1}^{\mathrm{a}_{\mathrm{i}}}+\frac{\alpha}{2} \mathrm{E}_{2}^{\mathrm{a}_{\mathrm{i}}}\right] \mathrm{x} \leq \frac{\alpha}{2} \mathrm{E}_{1}^{\mathrm{b}_{\mathrm{i}}}+\left(1-\frac{\alpha}{2}\right) \mathrm{E}_{2}^{\mathrm{b}_{\mathrm{i}}} \quad \mathrm{i}=1 \ldots \ldots \mathrm{m} . \mathrm{x} \geq 0 \quad \alpha \in[0,1]} \\
& {\left[\left(1-\frac{\alpha}{2}\right) E_{2}^{a_{i}}+\frac{\alpha}{2} E_{1}^{a_{i}}\right] x \geq \frac{\alpha}{2} E_{2}^{b_{i}}+\left(1-\frac{\alpha}{2}\right) E_{1}^{b_{i}} \quad i=1 \ldots \ldots . x \geq 0 \quad \alpha \in[0,1]}
\end{aligned}
$$

Consequently by applying this approach to the previously defined FMILP model, and by considering trapezoidal fuzzy numbers for the uncertain parameters, we obtain an auxiliary crisp mixed-integer 
linear programming model (MILP) as follows:

$$
\begin{aligned}
& \text { Minimize } \mathrm{z}=\sum_{\mathrm{i}=1}^{\mathrm{I}} \sum_{\mathrm{n}=1}^{\mathrm{N}} \sum_{\mathrm{j}=1}^{\mathrm{J}} \sum_{\mathrm{t}=1}^{\mathrm{T}} \sum_{\mathrm{m}=1}^{\mathrm{M}}\left(\frac{\mathrm{pc}_{\text {injtm } 1+} \mathrm{pc}_{\text {injtm } 2}+\mathrm{pc}_{\text {injtm } 3}+\mathrm{pc}_{\text {injtm } 4}}{4} \cdot \mathrm{p}_{\text {injtm }}\right)+ \\
& \sum_{\mathrm{n}=1}^{\mathrm{N}} \sum_{\mathrm{j}=1}^{\mathrm{J}} \sum_{\mathrm{t}=1}^{\mathrm{T}}\left(\frac{\mathrm{OC}_{\mathrm{njt} 1}+\mathrm{OC}_{\mathrm{njt} 2}+\mathrm{OC}_{\mathrm{njt} 3}+\mathrm{OC}_{\mathrm{njt} 4}}{4} \cdot \mathrm{OT}_{\mathrm{njt}}+\frac{\mathrm{UC}_{\mathrm{njt} 1}+\mathrm{UC}_{\mathrm{njt} 2}+\mathrm{UC}_{\mathrm{njt} 3}+\mathrm{UC}_{\mathrm{njt} 4}}{4} \cdot \mathrm{UT}_{\mathrm{njt}}\right)+ \\
& \sum_{\mathrm{i}=1}^{\mathrm{I}} \sum_{\mathrm{n}=1}^{\mathrm{N}} \sum_{\mathrm{t}=1}^{\mathrm{T}}\left(\mathrm{RMC}_{\mathrm{int}} \cdot \mathrm{PQ}_{\mathrm{int}}+\frac{\mathrm{HC}_{\mathrm{int} 1}+\mathrm{HC}_{\mathrm{int} 2}+\mathrm{HC}_{\mathrm{int} 3}+\mathrm{HC}_{\mathrm{int} 4}}{4} \cdot \mathrm{I}_{\mathrm{int}}+\right. \\
& \left.\frac{\mathrm{BC}_{\text {int } 1}+\mathrm{BC}_{\text {int } 2}+\mathrm{BC}_{\text {int } 3}+\mathrm{BC}_{\text {int } 4}}{4} \text {. } \mathrm{B}_{\text {int }}\right)+ \\
& \sum_{\mathrm{i}=1}^{\mathrm{I}} \sum_{\mathrm{o}=1}^{\mathrm{O}} \sum_{\mathrm{d}=1}^{\mathrm{D}} \sum_{\mathrm{l}=1}^{\mathrm{L}} \sum_{\mathrm{t}=1}^{\mathrm{T}}\left(\frac{\mathrm{TC}_{\text {odlt } 1}+\mathrm{TC}_{\text {odlt } 2}+\mathrm{TC}_{\text {odlt } 3}+\mathrm{TC}_{\text {odlt } 4}}{4} . \mathrm{TQ}_{\text {odlt }}\right)
\end{aligned}
$$

\section{Subject to}

$\sum_{\mathrm{i}=1}^{\mathrm{I}} \mathrm{p}_{\text {injt }} \cdot\left((1-\alpha) \frac{\mathrm{PTP}_{\text {injt } 1}+\mathrm{PTP}_{\text {injt } 2}}{2}+\alpha \frac{\text { PTP }_{\text {injt } 3}+\mathrm{PTP}_{\text {injt }} 4}{2}\right) \leq$

$(1-\alpha) \frac{\mathrm{PCR}_{\mathrm{njt} 3}+\mathrm{PCR}_{\mathrm{njt} 4}}{2}+\alpha \frac{\mathrm{PCR}_{\mathrm{njt} 1}+\mathrm{PCR}_{\mathrm{njt} 2}}{2}+(1-\alpha) \frac{\mathrm{PR}_{\mathrm{njt} 3}+\mathrm{OR}_{\mathrm{njt} 4}}{2}+\alpha \frac{\mathrm{OR}_{\mathrm{njt} 1}+\mathrm{OR}_{\mathrm{njt} 2}}{2} \quad \forall \mathrm{n}, \mathrm{j}, \mathrm{t}$

$$
\begin{aligned}
& \mathrm{P}_{\text {injt }} \cdot\left((1-\alpha) \frac{\text { PTP }_{\text {injt } 1}+\mathrm{PTP}_{\text {injt } 2}}{2}+\alpha \frac{\mathrm{PTP}_{\text {injt } 3}+\mathrm{PTP}_{\text {injt }} 4}{2}\right)+ \\
& \left((1-\alpha) \frac{\mathrm{PCR}_{\mathrm{njt} 1}+\mathrm{PCR}_{\mathrm{njt} 2}}{2}+\alpha \frac{\mathrm{PCR}_{\mathrm{njt} 3}+\mathrm{PCR}_{\mathrm{njt} 4}}{2}\right) . \mathrm{YP}_{\text {injt }}+ \\
& \left((1-\alpha) \frac{\mathrm{OR}_{\mathrm{njt} 1}+\mathrm{OR}_{\mathrm{njt} 2}}{2}+\alpha \frac{\mathrm{PR}_{\mathrm{njt} 3}+\mathrm{OR}_{\mathrm{njt} 4}}{2}\right) \text {. } \mathrm{YP}_{\text {injt }} \leq 0 \quad \forall \mathrm{n}, \mathrm{j}, \mathrm{t} \\
& \mathrm{SR}_{\text {iodlt }}=\mathrm{SR}_{\text {iodlt }}+\mathrm{TQ}_{\text {iodlt }-\mathrm{FTLT}} \quad \forall \mathrm{i}, \mathrm{o}, \mathrm{d}, \mathrm{l}, \mathrm{t} \quad \text { (30) } \\
& \sum_{\mathrm{i}=1}^{\mathrm{I}} \mathrm{I}_{\mathrm{int}} \cdot \mathrm{PV}_{\mathrm{it}} \leq(1-\alpha) \frac{\mathrm{UI}_{\mathrm{nt} 3}+\mathrm{UI}_{\mathrm{nt} 4}}{2}+\alpha \frac{\mathrm{UI}_{\mathrm{nt} 1}+\mathrm{UI}_{\mathrm{nt} 2}}{2} \quad \forall \mathrm{n}, \mathrm{t} \quad \text { (31) } \\
& \sum_{\mathrm{i}=1}^{\mathrm{I}} \sum_{\mathrm{o}=1}^{\mathrm{O}} \sum_{\mathrm{d}=1}^{\mathrm{D}} \mathrm{SIP}_{\text {iodlt }} \cdot \mathrm{PV}_{\mathrm{it}} \cdot \mathrm{X}_{\mathrm{odlt}}^{1}+\sum_{\mathrm{i}=1}^{\mathrm{I}} \sum_{\mathrm{o}=1}^{\mathrm{O}} \sum_{\mathrm{d}=1}^{\mathrm{D}} \mathrm{TQ}_{\text {iodlt }} \cdot \mathrm{PV}_{\mathrm{it}} \cdot \mathrm{X}_{\mathrm{odlt}}^{2} \leq(1-\alpha) \frac{\mathrm{UTC}_{\mathrm{lt} 3}+\mathrm{UTC}_{\mathrm{lt} 4}}{2}+ \\
& \alpha \frac{\mathrm{UTC}_{\mathrm{lt} 1}+\mathrm{UTC}_{\mathrm{lt} 2}}{2} \quad \forall \mathrm{l}, \mathrm{t} \\
& \sum_{\mathrm{i}=1}^{\mathrm{I}} \mathrm{PQ}_{\mathrm{int}} \leq(1-\alpha) \frac{\mathrm{UPS}_{\mathrm{nt} 3}+\mathrm{UPS}_{\mathrm{nt} 4}}{2}+\alpha \frac{\mathrm{UPS}_{\mathrm{nt} 1}+\mathrm{UPS}_{\mathrm{nt} 2}}{2} \quad \forall \mathrm{n}, \mathrm{t} \\
& \mathrm{B}_{\text {int }}-\mathrm{B}_{\text {in.t-1 }}+\mathrm{S}_{\text {int }} \leq\left(1-\frac{\alpha}{2}\right) \frac{\mathrm{D}_{\text {int } 1}+\mathrm{D}_{\text {int } 2}}{2}+\frac{\alpha}{2} \frac{\mathrm{D}_{\text {int } 3}+\mathrm{D}_{\text {int } 4}}{2} \forall \mathrm{i}, \mathrm{n}, \mathrm{t} \\
& \mathrm{B}_{\text {int }}-\mathrm{B}_{\text {in.t }-1}+\mathrm{S}_{\text {int }} \geq\left(1-\frac{\alpha}{2}\right) \frac{\mathrm{D}_{\text {int } 3}+\mathrm{D}_{\text {int } 4}}{2}+\frac{\alpha}{2} \frac{\mathrm{D}_{\text {int } 1}+\mathrm{D}_{\text {int } 2}}{2} \forall \mathrm{i}, \mathrm{n}, \mathrm{t} \\
& \cdot \sum_{\mathrm{i}=1}^{\mathrm{I}} \mathrm{P}_{\text {injt }}\left(1-\frac{\alpha}{2}\right) \frac{\mathrm{PTP}_{\text {injt } 1}+\mathrm{PTP}_{\text {injt } 2}}{2}+\frac{\alpha}{2} \frac{\mathrm{PTP}_{\text {injt } 3}+\mathrm{PTP}_{\text {injt }} 4}{2}+\mathrm{TOC}_{\text {njt }}-\mathrm{Tex}_{\mathrm{njt}} \leq \\
& \left(\left(1-\frac{\alpha}{2}\right) \frac{\mathrm{PCR}_{\mathrm{njt} 1}+\mathrm{PCR}_{\mathrm{njt}} 2}{2}+\alpha \frac{\mathrm{PCR}_{\mathrm{njt}} 3+\mathrm{PCR}_{\mathrm{njt}} 4}{2}\right) \forall \mathrm{n}, \mathrm{j}, \mathrm{t} \\
& \sum_{\mathrm{i}=1}^{\mathrm{I}} \mathrm{P}_{\text {injt }} \cdot\left(1-\frac{\alpha}{2}\right) \frac{\mathrm{PTP}_{\text {injt } 3}+\mathrm{PTP}_{\text {injt } 4}}{2}+\frac{\alpha}{2} \frac{\mathrm{PTP}_{\text {injt } 1}+\mathrm{PTP}_{\text {injt } 2}}{2}+\mathrm{TOC}_{\text {njt }}-\mathrm{Tex}_{\text {njt }} \geq \\
& \left(\left(1-\frac{\alpha}{2}\right) \frac{\mathrm{PCR}_{\mathrm{njt} 3}+\mathrm{PCR}_{\mathrm{njt}} 4}{2}+\alpha \frac{\mathrm{PCR}_{\mathrm{njt} 1}+\mathrm{PCR}_{\mathrm{njt} 2}}{2}\right) \forall \mathrm{n}, \mathrm{j}, \mathrm{t}
\end{aligned}
$$




$$
\begin{aligned}
& \sum_{\mathrm{n}=1}^{\mathrm{N}} \sum_{\mathrm{t}=1}^{\mathrm{T}} \mathrm{S}_{\text {int }} \leq \sum_{\mathrm{n}=1}^{\mathrm{N}} \sum_{\mathrm{t}=1}^{\mathrm{T}}\left((1-\alpha) \frac{\mathrm{D}_{\text {int } 3}+\mathrm{D}_{\text {int } 4}}{2}+\alpha \frac{\mathrm{D}_{\text {int } 1}+\mathrm{D}_{\text {int } 2}}{2}+\mathrm{BO}_{\text {int }}\right) \quad \forall \mathrm{i} \\
& \mathrm{FTLT}_{\text {odlt }} \leq \frac{\alpha}{2} \frac{\mathrm{TLT}_{\text {odlt } 1}+\mathrm{TLT}_{\text {odlt } 2}}{2}+\left(1-\frac{\alpha}{2}\right) \frac{\mathrm{TLT}_{\text {odlt } 3}+\mathrm{TLT}_{\text {odlt } 4}}{2} \forall \text { o.d.l.t } \\
& \mathrm{FTLT}_{\text {odlt }} \geq \frac{\alpha}{2} \frac{\mathrm{TLT}_{\text {odlt } 3}+\mathrm{TLT}_{\text {odlt } 4}}{2}+\left(1-\frac{\alpha}{2}\right) \frac{\mathrm{TLT}_{\text {odlt } 1}+\mathrm{TLT}_{\text {odlt } 2}}{2} \forall \text { o.d.l.t }
\end{aligned}
$$

FTLT $_{\text {odlt }} \geq 0 \quad \forall$ o.d.l.t

The non fuzzy constraints have also to be included in the model as in the original way.

\subsection{Interactive resolution method}

Here, an interactive resolution method which allows us to take a decision interactively with the DM is presented. This method is organized in three steps.

In the first step of our method the auxiliary crisp mixed-integer linear programming model defined above is solved parametrically in order to obtain the values of the decision variables and the objective function for each $\mathrm{c} \in[\mathrm{O}, \mathrm{l}]$. Then we apply a method of evaluation (extended from [58]) for the validation of models according to the following group of measurable parameters: (i) the average service level; (ii) inventory cost; (iii) planning nervousness with regard to the planned period; (iv) planning nervousness with regard to the planned quantity and (v) total costs.

(i) The average service level for the finished good is calculated as follows:

Average service level (\%) $=\sum_{\mathrm{t}=1}^{\mathrm{T}} \frac{\left(1-\frac{\mathrm{B}_{\text {int }}}{\sum_{\mathrm{t}=1}^{\mathrm{T}} \mathrm{D}_{\text {int }}}\right) \times 100}{\mathrm{~T}} \forall \mathrm{i}, \mathrm{n}$

(ii) The inventory cost is calculated as the sum of the inventory holding cost of the finished good and parts at the end of each planning period.

(iii) Planning nervousness with regard to the planned period. "Nervous" or unstable planning refers to a plan which undergoes significant variations when incorporating the demand changes between what is foreseen and what is observed in successive plans, as defined by [59]. Planning nervousness can be measured according to the demand changes in relation to the planned period or to the planned quantity. The demand changes in the planned period measure the number of times that a planned order is rescheduled, irrespectively of the planned quantity [60]. The next rule proposed by [61].is summarized as follows: At time $t$ we check for each period $t+x(x=0,1,2, \ldots, T$ $-1)$ :

If there is a planned order in $t+x$, and this order is not planned in the next planning run, we increase the number of reschedules by $\mathrm{l}$.

If there was no planned order in $t+x$, and there is one in the next planning run, we increase the number of reschedules by $\mathrm{l}$.

(iv) Planning nervousness with regard to the planned quantity measures the demand changes in the planned quantity as the number of times that the quantity of a planned order is modified [62].. The rule is described as follows:

In the period $t=1, \ldots, T$, where $T$ is the number of periods that forms the planning horizon, each period 
is checked so that $\mathrm{t}+\mathrm{x}(\mathrm{x}=0, \mathrm{l}, 2, \ldots, \mathrm{T}-\mathrm{l})$ :

If a planned order exists in the period $t+x$, then if the quantity of the planned order is not the same as in the next planning run, we increase the number of reschedules by $l$.

In the computation of planning nervousness, we measure the number of changes. Another way to compute it would be to take into account the rate of the changes.

(v) Total costs are the sum of all the costs that are generated in every period of the considered planning horizon, and derived from the procurement, production and distribution plans provided by the model.

In order to obtain a decision vector that complies with the expectations of the DM, we should evaluate two conflicting factors: the feasibility degree $o$ and the reaching of an acceptable value for the different parameters.

In the second step of our method, after seeing the results obtained in the first step, the DM is asked to specify an aspiration level $G$ and its tolerance threshold $t$ for the numerical values obtained by each evaluation parameter. In the case of "less is better", that is, inventory cost, nervousness and total cost, the DM's satisfaction level is expressed by means of a fuzzy set $\tilde{G}$ whose membership function is as follows [49].:

$\mu_{G}(z)=\left\{\begin{array}{c}1 \text { if } z \leq G \\ \lambda \in[0,1] \text { decreasing on } G \leq z \leq G+1 \\ 0 \text { if } z \geq G+1\end{array}\right.$

Symmetrically in the case "more is better", that is, in service level the goal is expressed by an increasing membership function:

$\mu_{G}(z)=\left\{\begin{array}{c}1 \text { if } z \geq G \\ \lambda \in[0,1] \text { decreasing on } G-t \leq z \leq G \\ 0 \text { if } z \leq G-t\end{array}\right.$

We define $\lambda \mathrm{i}(\mathrm{i}=\mathrm{l}, \ldots, 5)$ as the degree in which the corresponding fuzzy aspiration levels of the above parameters are satisfied by a decision vector. Obviously the DM wants to obtain a maximum satisfaction degree for all of them. In order to aggregate them we propose the weighted sum. The weight wi $(i=1, \ldots, 5)$ assigned by the DM to each parameter have been determined, as in the analytic hierarchy process[63], by the eigenvalues of the matrix of pairwise ratios whose rows give the ratios of weights of each parameter with respect to all others.

Thus we obtain the following global satisfaction degree (where $\sum_{\mathrm{i}} \mathrm{w}_{\mathrm{i}}=1$ ): $\mathrm{A}=\sum_{\mathrm{i}} \mathrm{w}_{\mathrm{i}} \lambda_{\mathrm{i}}=$ $\mathrm{w}_{1} \lambda_{1}+\mathrm{w}_{2} \lambda_{2}+\mathrm{w}_{3} \lambda_{3}+\mathrm{w}_{4} \lambda_{4}+\mathrm{w}_{5} \lambda_{5}$

But, in general, a lower level of the feasibility degree $\alpha$ will be achieved to obtain a better satisfaction degree K. Given these circum stances, the DM might require lower satisfaction in exchange for a better feasibility.

In the third step of our method, in an attempt to find a balanced solution between the feasibility degree o and the global satisfaction degree $\mathrm{K}$, we propose to build two fuzzy sets whose membership functions represent the DM's acceptation of the feasibility degree, $\gamma 0$, and the acceptation of the satisfaction degree, $\gamma \mathrm{K}$, respectively. The respective acceptation degrees, $\gamma_{\mathrm{o}}$ and $\gamma \mathrm{K}$, increase monotonously between the 
corresponding lower and upper bounds defined by the DM.

Observe that, when the DM built the fuzzy set related with the acceptation of the feasibility degree, $\gamma_{0}$, he/she is implicitly manifesting his/her aptitude against the risk of unfeasibility and when he/she built the fuzzy set related with the acceptation of the satisfaction degree, $\gamma \mathrm{K}$, he/she is manifesting his/her aptitude regarding to the attainment of good results.

In order to obtain a recommendation for a final decision, we calculate a joint acceptation index $\mathrm{K}$ by aggregating, through the weightedmean, the two aforementioned acceptation degrees.

$\mathrm{K}=\left\{\begin{array}{c}\beta \cdot \gamma_{\alpha}+(1-\beta) \cdot \gamma_{\mathrm{A}} \text { if } \gamma_{\alpha} \neq 0 \text { and } \gamma_{\mathrm{A}} \neq 0 \\ \text { otherwise }\end{array}\right.$

where $\beta \in[0,1]$ is the relative importance, assigned by the $\mathrm{DM}$, to the feasibility in comparison with the satisfaction.

\section{Conclusion}

Supply chain planning in an uncertainty environment is a complex task. This paper has proposed a novel fuzzy mixed-integer linear programming (FMILP) model for tactical SC planning by integrating procurement, production and distribution planning activities into a multi-echelon, multi-product, multilevel and multi-period SC network. The fuzzy model integrally handles all the epistemic uncertainty sources identified in SC tactical planning problems given a lack of knowledge (demand, process and supply uncertainties). This model takes a long time to be run and since in real environments short execution time model is essential, continued research will be performed by the algorithms and techniques on how to solve meta heuristic models and how to shorten the execution time and the planning range in real environments. Therefore, research and development will continue.

\section{References}

[1] Oliver, R.K., Webber, M.D., 1982. Supply-chain management: logistics catches up with strategy Outlook; cit. Christopher, M.G. Logistics (1992), The Strategic Issue. Chapman and Hall, London.

[2] Houlihan, J., 1984. Supply chain management. In: Proceedings of the 19th International Technical Conference of the British Production and Inventory Control Society. pp. 101-110.

[3] Christopher, M., 1992. Logistics and Supply Chain Management: Strategies for Reducing Costs and Improving Services. Pitman Editor.

[4] Lambert, D.M.,Cooper, M.C., 2000. Issues in supply chain management. Industrial Marketing Management 29 (1), 6583.

[5] Gupta, A., Maranas, C.D., 2003. Managing demand uncertainty in supply chain planning. Computers and Chemical Engineering 27 (8-9), 1219-1227. Heilpern, S., 1992. The expected value of a fuzzy number. Fuzzy Sets and Systems 47 (1), 8l-86.

[6] Bhatnagar, R., Sohal, A.S., 2005. Supply chain competitiveness: measuring the impact of location factors, uncertainty and manufacturing practices. Technovation 25 (5), 443-456.

[7] Mula, J., Poler, R., Garc'ia, J.P., Ortiz, A., 2005. Demand uncertainty effects of first tier suppliers of an automobile industry supply chain. The ICFAI Journal of Supply Chain Management 2-3, 19-39.

[8] Mula, J., Poler, R., Garcia-Sabater, J.P., Lario, F.C., 2006a. Models for production planning under uncertainty: a review. International Journal of Production Economics 103, 271-285

[9] Escudero, L.F., 1994. CMIT, capacitated multi-level implosion tool. European Journal of Operational Research 76, 511-528.

[10] Dubois, D., Fargier, H., Fortemps, P., 2002. Fuzzy scheduling: modelling flexible constraints vs. coping with incomplete knowledge. European Journal of Operational Research 147, 231-252.

[11] Dubois, D., Prade, H., (1988). Possibility Theory. New York, London.

[12] Park, Y.B., 2005. An integrated approach for production and distribution planning in supply chain management. International Journal of Production Research 43 (6), 1205-1224

[13] Dubois, D., Fargier, H., Fortemps, P., 2003. Fuzzy scheduling: modelling flexible constraints vs. coping with incomplete knowledge. European Journal of Operational Research 147 (2), 231-252.

[14] Peidro, D., Mula, J., Poler, R.l., Lario, F.C., 2009. Quantitative models for supply chain planning under uncertainty: a review. The International Journal of Advanced Manufacturing Technology 43 (3-4), 400-420.

[15] Petrovic, D., Roy, R., Petrovic, R., 1998. Modelling and simulation of a supply chain in an uncertain environment. European Journal of Operational Research 109 (2), 299-309.

[16] Petrovic, D., Roy, R., Petrovic, R., 1999. Supply chain modelling using fuzzy sets. International Journal of Production Economics 59 (1-3), 443-453. 


\section{Hamid Reza Feili, Mojdeh Hassanzadeh Khoshdooni/ TJMCS Vol .2 No.1 (2011) 65-80}

[17] Petrovic, D., 200l. Simulation of supply chain behaviour and performance in an uncertain environment. International Journal of Production Economics 7l (1-3), 429-438.

[18] Giannoccaro, I., Pontrandolfo, P., Scozzi, B., 2003. A fuzzy echelon approach for inventory management in supply chains. European Journal of Operational Research 149 (1), 185-196

[19] Clark, T.H., Scarf, H., 1960. Optimal polices for a multi-echelon inventory problem. Management Science 6, 475-490.

[20] Carlsson, C., Fuller, R., 2002. A fuzzy approach to taming the bullwhip effect. Advances in Computational Intelligence and Learning: Methods and Applications International Series in Intelligent Technologies 18, 247-262.

[21] Wang, J.T., Shu, Y.F., 2005. Fuzzy decision modeling for supply chain management. Fuzzy Sets and Systems 150 (1), $107-127$.

[22] Xie, Y., Petrovic, D., Burnham, K., 2006. A heuristic procedure for the two-level control of serial supply chains under fuzzy customer demand. International Journal of Production Economics 102 (1), 37-50.

[23] Wang, J., Shu, Y.F., 2007. A possibilistic decision model for new product supply chain design. European Journal of Operational Research 177 (2), 1044-1061.

[24] Kumar, M., Vrat, P., Shankar, R., 2004. A fuzzy goal programming approach for vendor selection problem in a supply chain. Computers and Industrial Engineering 46 (1), 69-85.

[25] Kumar, M., Vrat, P., Shankar, R., 2006a. A fuzzy programming approach for vendor selection problem in a supply chain. International Journal of Production Economics lOl (2),273-285.

[26] Zimmermann, H.J., 1978. Fuzzy programming and linear programming with several objective functions. Fuzzy Sets and Systems 1, 45-55.

[27] Amid, A., Ghodsypour, S.H., O’Brien, C., 2006. Fuzzy multiobjective linear model for supplier selection in a supply chain. International Journal of Production Economics 104 (2),394-407.

[28] Kumar, V., Prakash, Tiwari, M.K., Chan, F.T.S., 2006b. Stochastic make-to-stock inventory deployment problem: an endosymbiotic psychoclonal algorithm based approach.International Journal of Production Research 44 (11), $2245-$ 2263.

[29] Chanas, S., 1983. The use of parametric programming in fuzzy linear-programming. Fuzzy Sets and Systems ll (3), 243-25l.

[30] Shih, L.H., 1999. Cement transportation planning via fuzzy linear programming. International Journal of Production Economics 58 (3), 277-287.

[31] Zimmermann, H.J., 1976. Description and optimization of fuzzy systems. International Journal of General Systems 2 (4), 209-215.

[32] Chanas, S., 1983. The use of parametric programming in fuzzy linear-programming. Fuzzy Sets and Systems ll (3), 243-25l.

[33] Julien, B., 1994. An extension to possibilistic linear-programming. Fuzzy Sets and Systems 64 (2), $195-206$.

[34] Liu, S.T., Kao, C., 2004. Solving fuzzy transportation problems based on extension principle. European Journal of Operational Research 153 (3), 661- 674.

[35] Zadeh, L.A., 1978. Fuzzy sets as a basis for a theory of possibility. Fuzzy Sets and Systems l, 3-28.

[36] Liang, T.F., 2006. Distribution planning decisions using interactive fuzzy multi-objective linear programming. Fuzzy Sets and Systems 157 (10), 1303-1316.

[37] Sakawa, M., Nishizaki, I., Uemura, Y., 200l. Fuzzy programming and profit and cost allocation for a production and transportation problem. European Journal of Operational Research 131 (1), 1-15.

[38] Liang, T.F., 2007. Applying fuzzy goal programming to production/transportation planning decisions in a supply chain so. International journal of systems science 38 (4), 293-304.

[39] Selim, H., Araz, C., Ozkarahan, I., 2008. Collaborative production-distribution planning in supply chain: a fuzzy goal programming approach. Transportation Research Part E: Logistics and Transportation Review 44 (3), 396-419.

[40] Aliev, R.A., Fazlollahi, B., Guirimov, B.G., Aliev, R.R., 2007. Fuzzy-genetic approach to aggregate productiondistribution planning in supply chain management. InformationSciences 177 (20), 424l-4255.

[41] Chen, S.P., Chang, P.C., 2006. A mathematical programming approach to supply chain models with fuzzy parameters. Engineering Optimization 38 (6), 647-669.

[42] Torabi, S.A., Hassini, E., 2008. An interactive possibilistic programming approach for multiple objective supply chain master planning. Fuzzy Sets and Systems 159 (2), 193-214.

[43] Peidro, D., Mula, J., Poler, R., 2007. Supply chain planning under uncertainty: a fuzzy linear programming approach In: IEEE International Fuzzy Systems Conference, FUZZ- IEEE, pp. l-6.

[44] Buckley, J.J., 1989. Solving possibilistic linear-programming problems. Fuzzy Sets and Systems 31 (3), 329-341.

[45] Cadenas, J.M., Verdegay, J.L., 1997. Using fuzzy numbers in linear programming. IEEE Transactions on Systems Man and Cybernetics Part B - Cybernetics 27 (6), 1016-1022.

[46] Carlsson, C., Korhonen, P., 1986. A parametric approach to fuzzy linear-programming. Fuzzy Sets and Systems 20 (1), $17-30$.

[47] Gen, M., Tsujimura, Y., Ida, K., 1992. Method for solving multiobjective aggregate production planning problem with fuzzy parameters. Computers and Industrial Engineering 23 (1-4), ll7-l2O.

[48] Herrera, F., Verdegay, J.L., 1995. Three models of fuzzy integer linear programming. European Journal of Operational Research 83 (3), 581-593.

[49] Jiménez, M., Arenas, M., Bilbao, A., guez, M.V., 2007. Linear programming with fuzzy parameters: an interactive method resolution. European Journal of Operational Research 177, 1599-1609.

[50] Lai, Y.J., Hwang, Ch. L., 1992. Fuzzy Mathematical Programming: Methods and Applications. Springer-Verlag, Heidelberg.

[51] Vasant, P.M., 2005. Fuzzy linear programming for decision making and planning under uncertainty. International Journal of Information Technology and Decision Making 4 (4), 647-662. 
Hamid Reza Feili, Mojdeh Hassanzadeh Khoshdooni/ TJMCS Vol .2 No.1 (2011) 65-80

[52] Sakawa, M., 1993. Fuzzy Sets and Interactive Multi-objective Optimization. Plenum Press, New York.

[53] Lai, Y.L., Hwang, C.L., 1994. Fuzzy Multiple Objective Decision Making. Springer-Verlag, Berlin, Heildelberg.

[54] Rommelfanger, H., Slowinski, R., 1998. Fuzzy linear programming with single or multiple objective functions. In: Slowinski, R. (Ed.), Fuzzy Sets in Decision Analysis, Operation Research and Statistics. Kuwler Academic Publishers, Boston

[55] Wang, X., Kerre, E., 1996. On the classification and the dependencies of the ordering methods. In: Ruan, D. (Ed.), Fuzzy Logic Foundation and Industrial Applications,

[56] Jimenez, M., 1996. Ranking fuzzy numbers through the comparison of its expected intervals. International Journal of Uncertainty Fuzziness and Knowledge-Based Systems 4(4), 379-388.

[57] Heilpern, S., 1992. The expected value of a fuzzy number. Fuzzy Sets and Systems 47 (1), 81-86.

[58] Mula, J., Poler, R., Garc'1a, J.P., 2006. MRP with flexible constraints: a fuzzy mathematical programming approach. Fuzzy Sets and Systems 157 (1), 74-97.

[59] Sridharan, V., Berry, W., Udayabhanu, V., 1987. Freezing the master production schedule stability under rolling planning horizons. Management Science 33 (9), ll37-l149.

[60] Heisig, G., 1998. Planning stability under (s,S) inventory control rules. OR Spectrum 20 (4), 215-228.

[61] Donselaar, K.V., Nieuwenhof, J.V., Visschers, J., 2000. The impact of material coordination concepts on planning stability in supply chains. International Journal of Production Economics 68, 169-176.

[62] de Kok, T., Inderfurth, K., 1997. Nervousness in inventory management: comparison of basic control rules. European Journal of Operational Research 103 (1), 55-82.

[63] Saaty, T.M., 1990. How to make a decision: the analytic hierarchy process. European Journal of Operational Research $48,9-16$. 